\title{
DEALING WITH DIVERSITY: ISSUES IN DESIGN RESEARCH AND DESIGN RESEARCH METHODS
}

Jonas Löwgren'1, \& Yukari Nagai²,

'School of Arts and Communication, Malmö University, Malmö, Sweden \& ${ }^{2}$ School of Knowledge

Science, Japan Advanced Institute of Science and Technology, Asahidai Nomi-city, Ishikawa, Japan

Design research is a timely topic, given the current movements in art and design institutions throughout the world towards articulation, conceptualization, and (academic) research, where labels such as practice-based research abound. It is also a challenging topic with many open issues concerning conceptual foundations and methodological practices. As the articles in this special issue will show, design research is marked by significant diversity in the sense that it engages researchers from many different disciplines: Philosophy, systems theory, social science, information science, architecture, and design are among the academic disciplines represented here, with all the diversity in epistemological and methodological traditions that they entail.

However, design research is also marked by a distinctive ambition to deal with the diversity implied by the multidisciplinary nature of its research community. Different analytical and generative perspectives have engaged in common discourse on the nature and practice of design ever since the origins of design studies in the 1950s. Some 30 years ago, British scholars introduced a distinction between research-into-design, research-for-design and research-through-design (also called research-by-design) in order to characterize the field. Even though the concepts have been somewhat contested, they have proven to be remarkably persistent and are still in common use. Research-into-design refers to studies of the activity of designing, whereas research-fordesign concerns the development of knowledge to support design practice and researchthrough- design refers to developing knowledge about a phenomenon by designing for it.

In our call for papers to the special issue, we drew on the intoforthrough distinction to list a range of questions, indicative of the sort of contributions we had in mind.
- Research-into-design: How can we study the activity of designing? What are the methodological conclusions and caveats? What are the characteristics of designing that have an impact on the choice of research methods?

- Research-for-design: What is design ability and how can it be developed? How can the development of design ability be facilitated by knowledge contributions from research? What does validation mean in relation to such knowledge contributions? What are the criteria for judging the quality of research results? How can we conduct research that leads to knowledge for design?

- Research-through-design: How can we conduct research through design? Can we construct knowledge about a phenomenon by designing for it? What is the nature of that knowledge? What is the role of the artifact in such knowledgeconstruction processes? What does validation mean in relation to knowledge constructed by designing? What are the criteria for judging goodness of research results? What are the epistemological foundations of exploring possible futures?

There are, of course, also general questions to be addressed, such as: What is design research? What should it be? What is the role of design research? What should it be?

The design research community responded to the call by submitting no less that 15 manuscripts, out of which we had the painful pleasure of selecting six. After a thorough process of double-blind reviewing, we arrived at a selection which collects up-todate experience and thoughts on design research, crucial issues for taking the field further, and best practices in design research methodology. The contributions offered by the distinguished authors report on theoretical and methodological findings 
in design research, or reflect on theoretical and methodological issues in design research, rather than examples of design research per se.

The article by Gavin Melles opens the issue by proposing pragmatism, properly understood, as a reliable epistemological framework for methodological pluralism in design research. Melles provides a historical account of an "intellectually robust and ideologically critical" version of pragmatism, and outlines how it could give meaning to currently rather ad-hoc methodological diversity while recognizing the fundamentally wicked nature of design "solution-making".

The next three articles, considered together, amply illustrate the diversity of design research in terms of perspectives as well as methodology. Ingbert Floyd, Cameron Jones, and Michael Twidale provide a close look at a particular method for design research and design practice, namely the construction of personas. What they provide through their "theoretical decomposition" is a classification scheme for kinds, attributes, and characteristics of personas, based on the existing methodological literature but providing insights that go beyond it. As suggested by the authors, the approach is applicable also to other parts of the methodological canon of design research.

Toshiharu Taura considers how the "back and forth" problem in the design process can be treated as a spatial problem. In particular, he explores the nature of functional decomposition and creative recombination in design, in order to examine the essential issue of design process as a spatial problem in the mathematical-topological sense.

In his article, Anders Brix asks the question of what kind of knowledge is embedded in the great artifacts making up the canons of industrial and architectural design. His provisional answer is that they simultaneously exhibit enough richness and coherence to serve as focal points of sustained design discourse, a quality which Brix calls solidity.

The final two articles go deeper into the theme opened up by Brix, i.e. the role and treatment of design artifacts and design activities in design research. John Zimmerman and Jodi Forlizzi lay out an ambitious call for "generalizable, systematic approaches" to developing theory based on artifacts created as part of the research process, drawing on the field of interaction design for their illustrations.
Ilpo Koskinen, Thomas Binder, and Johan Redström analyze the practice of research-throughdesign in the last 10 years, identifying three broad approaches called the Lab, the Field, and the Gallery. They demonstrate how these three approaches integrate design activities into research processes in different ways. The article concludes with a discussion of the relations between design research and the epistemological and methodological standards of the disciplines making up the multifaceted intellectual heritage of design research.

We find that the concluding remarks by Koskinen, Binder, and Redström work well as a note on which to close the special issue. Design research deals with diversity, and the question of how it should deal with the heritage of its disciplinary ancestors and neighbors is not one to be answered once and for all. Rather, it has to be revisited and reassessed every time a design researcher approaches a research problem. This special issue is intended to support such ongoing and reflective work.

\section{ACKNOWLEDGEMENTS}

We could not have put this issue together without the efforts of the anonymous reviewers who provided an exceptional amount of scientific community service through their constructive criticism and sharp judgments. In order to preserve the integrity of the review process, we cannot list your names here - but you know who you are. Thank you!

\section{CORRESPONDENCE}

Jonas Löwgren,

School of Arts and Communication, Malmö University, 20506 Malmö, Sweden.

E-mail: jonas.lowgren@mah.se

Published online 28 November, 2008 ISSN 1749-3463 print/ ISSN 1749-3471

DOI: $10.1080 / 17493460802276760$

(C) 2008 Artifact 